\title{
Challenges of training and delivery of pediatric surgical services in developing economies: a perspective from Pakistan
}

\author{
Amir Humza Sohail ${ }^{1}$, Muhammad Hassaan Arif Maan ${ }^{2 *}$, Mohammed Sachal ${ }^{3}$ and Muhammad Soban ${ }^{4}$
}

\begin{abstract}
Background: As the pediatric population requiring health services rises globally, developing countries are struggling to cater to the growing burden of non-communicable diseases - particularly those requiring specialized surgical care.

Main body: Despite the literature supporting specialized pediatric surgical care, the developing world is far from meeting the American Pediatric Surgical Association (APSA) Manpower taskforce recommendation of at least 1 qualified pediatric surgeon per 100,000 patients (0-15 years-old). In Pakistan, there is an unmet surgical need in the pediatric population due to a multitude of short shortcomings, notably in quality and quantity of the training programs on offer, and urgent short- and long-term steps are needed to improve this dire situation.
\end{abstract}

Conclusion: It is crucial for the global surgical community to take steps, especially with regards to pediatric surgical training, to ensure delivery of accessible and quality surgical care to the world's children.

Keywords: Pediatric surgery, Pediatric workforce, Specialized surgical care, Low- and middle-income countries

\section{Background}

The pediatric population requiring health services is rising globally. [1] Interestingly, while tremendous advances have been made in the formulation of evidence-based strategies and policies geared towards prevention and management of communicable diseases in this population group, non-communicable diseases - particularly those requiring specialized surgical care - are often neglected, especially in developing countries. Furthermore, improved outcomes have been associated with care provided by pediatric surgical subspecialists with advanced training for children requiring surgery than that delivered by other healthcare professionals. [2-12] Thus, it is crucial to ensure the provision of relevant infrastructure and pediatric surgery training opportunities to cater to the ever-growing burden of surgical conditions in the pediatric population.

\section{Main text}

The American Pediatric Surgical Association (APSA) Manpower taskforce recommends that the number of

\footnotetext{
* Correspondence: m.hassaanmaan@gmail.com

${ }^{2}$ Medical College, The Aga Khan University, Stadium Road, Karachi, Pakistan Full list of author information is available at the end of the article
}

qualified pediatric surgeons in a population should be at least 2 per million (or 1 per 100,000 patients between 0 and 15 years of age). [13] Even though only a handful of countries (e.g. the US, Finland, Canada, Australia and Switzerland) meet the above-mentioned standards, the growth rate of pediatric surgical graduates' numbers in the western world in recent years is higher than that previously forecasted, which provides some reassurance. $[13,14]$ However, data from developing countries are less encouraging. For instance, the reported numbers of pediatric surgeons (per hundred thousand population) in Asian countries (e.g. Bangladesh, 0.30; India, 0.28; Pakistan, 0.26; Indonesia, 0.03; and Malaysia, 0.22) is suboptimal. [14] This shortage of pediatric surgeons, in conjunction with other hurdles to quality healthcare in resource-limited settings, has dire consequences for population health. For example, according to an estimate in 2015, Nepal has more than 700,000 children with unmet needs for surgical care. [15] Butler et al., while focusing on four low- and middle-income countries (LMICs) (Rwanda, Sierra Leone, Nepal and Uganda) found that $62 \%$ of children (3.4 million children) in need of surgical intervention had not received the required care. [16] This highlights the need to bridge gaps in 
provision of specialized pediatric surgical care in LMICs. In view of the growing global pediatric population and the mounting needs for surgical care that this entails, the current sub-optimally planned approach to pediatric surgery will inevitably lead to crises in health service delivery mechanisms, particularly in LMICs.

In Pakistan, reasons for the mismatch between the number of graduating pediatric surgeons and the growing population needs are manifold. [17] Pediatric surgery training involves post-graduate fellowships at major institutions under the aegis of College of Physicians and Surgeons, Pakistan (CPSP). [17] Variations in training programs offered by different institutions, despite the presence of a CPSP standardized curriculum, need to be addressed. Furthermore, we propose that greater exposure to pediatric surgery in formative medical training may result in greater motivation to pursue a career in pediatric surgery among young surgical/medical graduates. $[17,18]$ To tackle these issues, a multi-pronged strategy is required. Incorporation of some pediatric surgical care training into general surgical training programs will not only instill the required skills and confidence in general surgeons to handle pediatric patients, especially in rural areas without access to pediatric surgery specialists, but may also spawn their interest in this field as a potential fellowship option. Reforms to simplify the lengthy CPSP accreditation process could also pave the way for setting up of new fellowship programs.

\section{Conclusion}

Challenges, particularly shortage of training opportunities and administrative hurdles in developing pediatric surgery training programs, hamper delivery of accessible and quality surgical care to the world's children. The global surgical community and individuals in leadership roles, especially in developing economies, must recognize the need to address the current pitfalls and the emerging challenges in pediatric surgery.

\section{Abbreviations}

APSA: American Pediatric Surgical Association; CPSP: College of Physicians and Surgeons, Pakistan; LMIC: Low- and middle-income countries

\section{Acknowledgements}

Not applicable.

Funding

No funding was involved in preparation of this manuscript.

Availability of data and materials

Not applicable.

\section{Authors' contributions}

AHS presented the idea of this project. All the authors took part in literature search for this project. AHS and MHAM helped in writing the main body of the article. MS(third author) was involved in writing the Background and MS (fourth author) helped with Conclusion, manuscript revision (after peer review) and referencing. All authors were involved in the final editing of the manuscript. All authors have read and approved the final version of the manuscript.

Ethics approval and consent to participate

Not applicable.

Consent for publication

Not applicable.

\section{Competing interests}

The authors declare that they have no competing interests.

\section{Publisher's Note}

Springer Nature remains neutral with regard to jurisdictional claims in published maps and institutional affiliations.

\section{Author details}

'Department of Surgery, Howard University Hospital, Washington, DC, USA. ${ }^{2}$ Medical College, The Aga Khan University, Stadium Road, Karachi, Pakistan. ${ }^{3}$ King Edward Medical University, Lahore, Pakistan. ${ }^{4}$ The Aga Khan University, Karachi, Pakistan.

Received: 26 October 2018 Accepted: 12 April 2019

Published online: 16 May 2019

\section{References}

1. Harvey A, Towner E, Peden M, Soori H, Bartolomeos K. Injury prevention and the attainment of child and adolescent health. Bull World Health Organ. 2009:87:390-4.

2. Mooney DP, Birkmeyer NJO, Udell JV, et al. Variation in the management of pediatric splenic injuries in New Hampshire. J Pediatr Surg. 1998;33(7):1076-80.

3. Shah AA, Shakoor A, Zogg CK, Oyetunji T, Ashfaq A, Garvey EM, Latif A, Riviello R, Qureshi FG, Mateen A, Haider AH. Influence of sub-specialty surgical care on outcomes for pediatric emergency general surgery patients in a low-middle income country. Int J Surg. 2016;29:12-8.

4. McAteer JP, Kwon S, Lariviere CA, et al. Pediatric specialist care is associated with lower risk of bowel resection in children with intussusceptions: a population-based analysis. J Am Coll Surg. 2013;217(2):226-32.

5. Alexander F, Magnuson D, DiFiore J, et al. Specialty versus generalist care of children with appendicitis: an outcome comparison. J Pediatr Surg. 2001; 36(10):1510-3

6. Pranikoff T, Campbell BT, Travis J, et al. Differences in outcome with subspecialty care: pyloromyotomy in North Carolina. J Pediatr Surg. 2002;37(3):352-6.

7. Tejwani R, Wang HH, Young BJ, Greene NH, Wolf S, Wiener JS, Routh JC Increased pediatric sub-specialization is associated with decreased surgical complication rates for inpatient pediatric urology procedures. J Pediatr Urol. 2016;12(6):388-e1.

8. Rhee DS, Papandria DJ, Zhang Y, Ortega G, Colombani PM, Chang DC, Abdullah F. Comparison of pediatric surgical outcomes by the Surgeon's degree of specialization in children. J Surg Res. 2011;165(2):333.

9. Bickler SW, Rode H. Surgical services for children in developing countries. Bull World Health Organ. 2002:80:829-35.

10. Somme S, To T, Langer JC. Effect of subspecialty training on outcome after pediatric appendectomy. J Pediatr Surg. 2007;42(1):221-6.

11. Borenstein $\mathrm{SH}, \mathrm{To} \mathrm{T}$, Wajja A, Langer JC. Effect of subspecialty training and volume on outcome after pediatric inguinal hernia repair. J Pediatr Surg. 2005:40(1):75-80.

12. Kokoska ER, Minkes RK, Silen ML, Langer JC, Tracy TF, Snyder CL, Dillon PA, Weber TR. Effect of pediatric surgical practice on the treatment of children with appendicitis. Pediatrics. 2001;107(6):1298-301.

13. Neill JA, Cnaan A, Altman RP, Donahoe PK, Holder TM, Neblett WW, Schwartz MZ, Smith CD. Update on the analysis of the need for pediatric surgeons in the United States. J Pediatr Surg. 1995;30(2):204-13.

14. Krishnaswami $\mathrm{S}$, Nwomeh B, Ameh E. The pediatric surgery workforce in low- and middle-income countries: problems and priorities. Semin Pediatr Surg. 2016;25(1):32-42.

15. Nagarajan N, Gupta S, Shresthra S, Varadaraj V, Devkota S, Ranjit A, Kushner AL, Nwomeh BC. Unmet surgical needs in children: a household survey in Nepal. Pediatr Surg Int. 2015;31(4):389-95. 
16. Butler EK, Tran TM, Nagarajan N, Canner J, Fuller AT, Kushner A, Haglund MM, Smith ER. SOSAS 4 country research group. Epidemiology of pediatric surgical needs in low-income countries. PLoS One. 2017;12(3):e0170968.

17. Akhtar J. Postgraduate training program in pediatric surgery: a way forward. APSP journal of case reports. 2011;2(1):1.

18. Saing $\mathrm{H}$. Training and delivery of pediatric surgery services in Asia. J Pediatr Surg. 2000;35(11):1606-11.

Ready to submit your research? Choose BMC and benefit from:

- fast, convenient online submission

- thorough peer review by experienced researchers in your field

- rapid publication on acceptance

- support for research data, including large and complex data types

- gold Open Access which fosters wider collaboration and increased citations

- maximum visibility for your research: over $100 \mathrm{M}$ website views per year

At $\mathrm{BMC}$, research is always in progress.

Learn more biomedcentral.com/submissions 